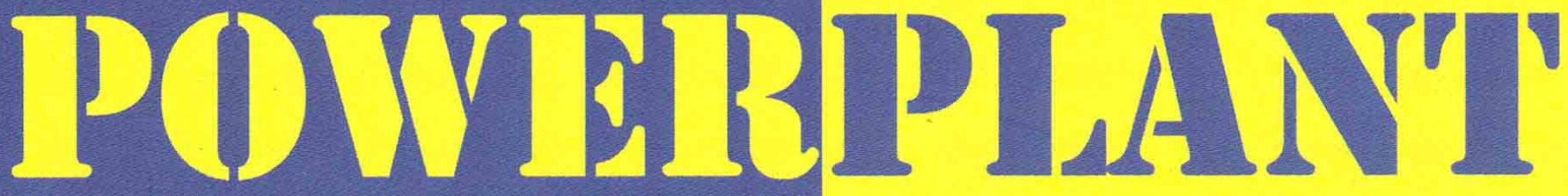

Nofirman:

Yusuf Rasyid

Vendy Antono;

Win Alfalah;

Rizky Windani

Eko Sulistiyo:

Utami Wahyuningsih:

M. Arif Rahman Sutisna

Sahlan

Vendy Antono;

Arief Suardi Nur Chairat;

Muhammad Husnuddin

Prayudi:

Roswati Nurhasanah

Hendri;

Suhengki:

Amru Fathony Lubis

Sri Yayi:

Jumiati;

Intan Ratna Sari Yanti
Pengaruh Kegagalan Terhadap Kinerja Chiller

Analisa Kegagalan Platen Tube SUperheater PLTU Teluk Sirih

Analisis Head Losses Pada Penstok Unit III Di Perum Jasa Tirta II Unit Jasa Pembangkit PLTA Ir. H.Djuanda

Kajian Terkait Industri Material HANKAM Dan

Kebencanaan Dari Sisi Pasar

Analisa Kerusakan Roda Gigi Cacing Pada Gearbox Air Preheater PLTU UJP Banten 3 Lontar Unit 1

Studi Eksperimental Kinerja Clod Strorage Mini dengan Refrigerant R2 dan R404A

Pengaruh Fouling Terhadap Laju Perpindahan Panas Pada Superheater Boiler CFB PLTU Sebalang

Pengaruh Jenis Pengetahuan Dan Kecakapan Terhadap Kemampuan Menulis Bahasa Inggris Pada Mahasiswa Teknik Mesin Sekolah Tinggi Teknik PLN

\begin{tabular}{|c|c|c|c|c|c|c|}
\hline$\|\mid\|$ & & SE & OLAH & VGGI TEKI & PL & \\
\hline
\end{tabular}




\title{
PENGARUH KEGAGALAN TERHADAP KINERJA CHILLER
}

\author{
Nofirman $^{1}$. Yusuf Rasyid ${ }^{2}$ \\ ${ }^{1}$ Fakultas Teknologi Industri, STT-PLN \\ Email: nofirman@sttpln.ac.id \\ yusfrasyid@gmail.com
}

\begin{abstract}
Dalam artikel ini kami melakukan analisa pengaruh delapan jenis kegagalan terhadap kW/Ton chiller dengan menggunakan regresi satu variabel. Kemudian hasil ini kami bandingkan dengan yang diperoleh dalam penelitian lain. Hasilnya adalah bahwa tidak semua kegagalan dapat dideteksi dengan perubahan nilai $\mathrm{kW/Ton}$ chiller dan tidak semua kegagalan menyebabkan naiknya konsumsi $k W / T o n$ chiller. Selain hal ini, jenis metode regresi dan satuan yang digunakan juga berpengaruh terhadap hasil $k W / T o n$ chiller.
\end{abstract}

\section{PENDAHULUAN}

Chiller merupakan sumber konsumsi energi terbesar untuk kebanyakan gedung komersial. Di banyak gedung komersial, chiller bisa mengkonsumsi listri 40-60\% dari total konsumsi listrik. Sebagaimana peralatan lainnya, semakin lama chiller beroperasi maka kinerja chiller akan menurun. Menurunnya kinerja chiller membuat chiller membutuhkan energi lebih banyak untuk menghasilkan beban pendinginan yang sama. Perbaikan kinerja akan menghasilkan penghematan energi yang cukup besar. Salah satu cara untuk mengembalikan kinerja adalah dengan tindakan pemeliharaan. Pemeliharaan yang tepat dalam jangka panjang dapat mengurangi atau mengendalikan konsumsi energi chiller [1]. Hal ini benar bila kita mengetahui apa yang harus dipelihara dan kapan melakukannya.

Terdapat dua jenis kegagalan; pertama adalah kegagalan yang terjadi secara acak (Random), kedua adalah kegagalan karena degradasi kinerja peralatan [2]. Kegagalan degradasi terjadi secara perlahan dan terus menerus dalam jangka panjang. Dalam jangka waktu pendek, sulit untuk mengetahui terjadinya degradasi atau penurunan kinerja suatu sistim. Pada chiller kegagalan degradasi kinerja dapat menyebabkan dua hal; turunnya kinerja chiller atau menurunnya beban pendinginan output chiller. Mengendalikan dua parameter tersebut (Kinerja dan beban pendingin) sangat penting dalam pengoperasian chiller yang andal dan efisien.

Penyebab kegagalan degradasi kinerja ini disebabkan oleh rendahnya level pemeliharaan dan monitoring chiller [3]. Tindakan pemeliharaan dan monitoring yang tepat dapat memperpanjang usia pakai chiller sampai dengan 50\% [3]. Disisi lain, sebuah studi juga menyatakan bahwa pemeliharaan pada chiller dapat menghemat energi 20-30\% [4]. Walaupun pemeliharaan yang dilakukan adalah hal sederhana seperti pembersihan kondensor dan evaporator, program pengolahan air baku yang baik, memoitor kebocoran refrigeran secara rutin [4].

Penelitian kami kali ini akan fokus kepada pengaruh kegagalan terhadap kinerja ( $\mathrm{kW} / \mathrm{Ton})$ chiller. Data eksperimental kegagalan yang dijadikan obyek penelitian adalah penelitian yang dilakukan oleh Comstock [5]. Berdasarkan data eksperimental inilah akan dilakukan analisa pengaruh masing-masing jenis kegagalan terhadap penurunan kinerja chiller (KW/TON).

\section{STUDI LITERATUR}

Sebelum melakukan usaha dan investasi untuk mengembangkan teknik untuk mendeteksi dan mendiagnosis kegagalan pada chiller (FDD), perlu diketahui jenis kegagalan apa saja yang dianggan penting sehingga perlu dimasukkan dalam program riset FDD. Untuk itu sebuah penelitian pernah dilakukan untuk melakukan survey kegagalan-kegagalan yang umum terjadi pada chiller [8]. Penelitian ini bertujuan untuk mengetahui jenis kegagalan yang paling sering terjadi, dan juga besarnya biaya relatif perbaikan yang dibutuhkan untuk masing-masing jenis kegagalan yang sering terjadi tersebut. Penelitian dilakukan berdasarkan data-data histori kegagalan yang 
diperoleh dari pabrikan-pabrikan chiller di Amerika Serikat.

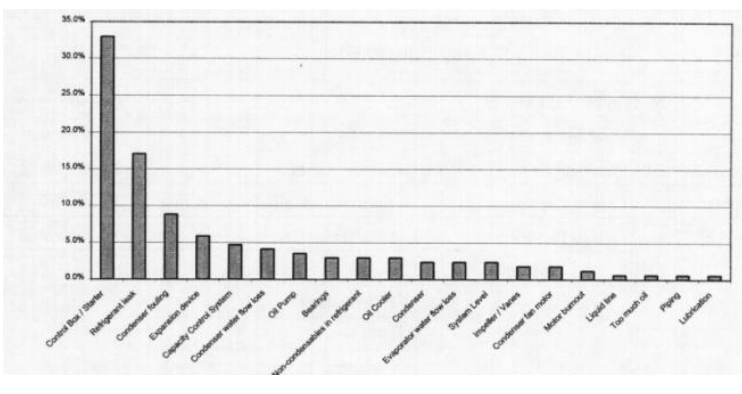

Gambar 1 Frekuensi jeni kegagalan pada chiller sentrifugal [8]

Berdasarkan hasil survey kegagalan pada chiller [8], kemudian Comstock melakukan percobaan ekperimental chiller untuk jenis kegagalan halus (Soft failure) yang berguna sebagai bank data dalam mengembangkan dan menguji atau memvalidasi metode FDD yang ada. Dari survey kegagalan yang terdapat pada Gbr 1 dan 2, akhirnya ditentukan 8 jenis kegagalan halus dari sekian jenis kegagalan yang ada. Delapan jenis kegagalan ini bisa dilihat di Tabel 1.

Tabel 1. Delapan kegagalan yang umum terjadi [8]

\begin{tabular}{c|l}
\hline No & \multicolumn{1}{|c}{ Fault test } \\
\hline 1 & Reduced Condenser Water Flow \\
2 & Reduced Evaporator Water Flow \\
3 & Refrigerant Leak \\
4 & Refrigerant Overcharge \\
5 & Excess Oil \\
6 & Condenser Fouling \\
7 & Non-Condensables in Refrigerant \\
8 & Defective Pilot Valve \\
\hline
\end{tabular}

Kami juga akan melakukan validasi menggunakan data mentah yang sama sebagaimana yang dilakukan comstock, perbedaannya adalah kami melakukan filter data dengan menggunakan kesetimbangan energi, dan hasilnya tidak boleh lebih dari $5 \%$.

\section{METODE PENELITIAN}

Data operasi kondisi normal adalah data akan digunakan sebagai pembanding (Benchmark) atau sebagai acuan (Baseline) untuk menentukan apakah terjadi penurunan
KW/TON chiller atau perubahan parameter operasi chiller yang lainnya.

Dalam hal ini, data mentah pada kondisi normal dilakukan percobaan selama beberapa kali, masing-masing percobaan terdapat 27 titik data [5]. Untuk memfilter data pada kondisi normal, dilakukan perhitungan kesetimbangan energi (Energy balance) pada sistim chiller. Perbedaan dalam hasil perhitungan ketimbangan energi tidak lebih dari 5\%. Data yang perbedaannya lebih dari 5\% tidak dimasukkan dalam analisa.

Dari hasil pengolahan dari data yang telah difilter akan dihitung KW/TON chiller berdasarkan hasil pengukuran daya kompresor, perhitungan beban kondenser dan evaporator yang tadi digunakan untuk memfilter data. Kemudian kami gambarkan grafik antara beban pendinginan (Cooling load) dengan KW/TON chiller. Data inilah yang digunakan sebagai baseline atau benchmarking untuk masingmasing kegagalan yang terjadi.

Untuk masing-masing jenis kegagalan (Tabel 1) akan dilakukan pemfilteran data dengan cara yang sama yaitu dengan melakukan perhitungan kesetimbangan energi, dan perbedaan perhitungan tidak lebih dari 5\%. Kemudian kita gambarkan hubungan antara $\mathrm{KW} / \mathrm{TON}$ dengan beban pendinginan (Cooling load) untuk masing-masing jenis kegagalan. Untuk masing-masing kegagalan terdapat beberapa level tingkat kegagalan (Severity) yaitu dari Level 1 sampai dengan level 4, dimana level 4 adalah tingkat kegagalannya paling parah (Severe).

Parameter acuan yang digunakan untuk masing-masing kegagalan menggunakan hasil riset yang dilakukan oleh Comstock [6]. Dari parameter-parameter yang penting untuk masing-masing kegagalan akan dibuat grafik yang menghubungkan pengaruh masing-masing parameter terhadap beban pendinginan, jenis kegagalan, dan level kegagalan yang dialami.

Hasil pengolahan data normal dengan masing-masing data kegagalan akan dibandingkan kinerja chiller (KW/TON) untuk masing-masing jenis dan level kegagalan dengan data kinerja chiller pada kondisi normal (Baseline). Selain itu, akan dilakukan perhitungan rata-rata penurunan $\mathrm{KW} / \mathrm{TON}$ chiller akibat kegagalan yang terjadi untuk masing-masing jenis dan level kegagalan chiller. 


\section{HASIL DAN PEMBAHASAN}

Kegagalan karena berkurangnya debit air kondensor (FWC) menyebabkan naiknya konsumsi energi $\mathrm{kW} /$ Ton pada setiap level kegagalan dibandingkan dengan kondisi normal (Tabel 2). Akan tetapi kenaikan $\mathrm{kW} /$ Ton pada kegagalan level 4 tidak sebesar pada level kegagalan yang lain. Pada beban evaporator yang rendah, perbedaan kenaikan $\mathrm{kW} /$ Ton untuk setiap kegagalan tidak terlalu besar. Perbedaan yang besar terjadi pada beban evaporator yang tinggi.

Selain air kondensor, kinerja chiller juga dipengaruhi oleh debit air evaporator (FWE). Kegagalan jenis ini menyebabkan menurunnya kinerja chiller dengan naiknya $\mathrm{kW} /$ Ton untuk setiap level kegagalan (Tabel.2), walaupun kenaikan kW/Ton pada kegagalan level 1 lebih besar dibandingkan level 2 dan 3 (Tabel.2). Hal ini berbeda dengan hasil yang diperoleh Comstock $^{(6)}$, dimana kenaikan $\mathrm{kW} /$ Ton terjadi secara gradual seiring dengan berkurangnya debit air evaporator (Tabel.2).

Kebocoran refrigeran adalah kegagalan jenis ketiga yang diuji oleh Comstock $(5,6)$. Simulasi dilakukan dengan cara mengurangi kapasitas refrigerant kelipatan 10\% dari kondisi normal untuk tiap level kegagalan. Pengaruh berkurangnya kapasitas refrigeran terhadap kinerja chiller ( $\mathrm{kW} / \mathrm{Ton})$ menunjukkan bahwa berkurangnya refrigeran justru meningkatkan kinerja chiller yang ditandai dengan menurunnya konsumsi energi $\mathrm{kW} / \mathrm{Ton}$ untuk setiap skenario kegagalan (Tabel 2 ). Sedangkan Comstock $^{(6)}$ mendapati bahwa kinerja chiller rata-rata menurun pada level kegagalan 1 dan 2, dan kemudian meningkat untuk level kegagalan 3 dan 4 (Tabel 2).

Tabel 2.Deviasi kW/Ton untuk tiap level kegagalan

\begin{tabular}{|c|l|c|c|c|c|}
\hline No & Debit air kondensor & Level 1 & Level 2 & Level 3 & Level 4 \\
\hline 1 & $\mathrm{~kW} /$ Ton & $19.3 \%$ & $29.3 \%$ & $31.2 \%$ & $6.4 \%$ \\
\hline 2 & $\mathrm{~kW} /$ Ton , Comstock [6] & $0.8 \%$ & $2.5 \%$ & $3.2 \%$ & $6.1 \%$ \\
\hline
\end{tabular}

\begin{tabular}{|c|l|c|c|c|c|}
\hline No & Debit air evaporator & Level 1 & Level 2 & Level 3 & Level 4 \\
\hline 1 & $\mathrm{~kW} /$ Ton & $50.7 \%$ & $39.1 \%$ & $34.9 \%$ & $56.9 \%$ \\
\hline 2 & $\mathrm{~kW} /$ Ton , Comstock [6] & $10.2 \%$ & $22.3 \%$ & $38.8 \%$ & $55.8 \%$ \\
\hline
\end{tabular}

\begin{tabular}{|c|l|c|c|c|c|}
\hline No & Kebocoran refrigerant & Level 1 & Level 2 & Level 3 & Level 4 \\
\hline 1 & $\mathrm{~kW} /$ Ton & $-17.1 \%$ & $-22.2 \%$ & $-33.3 \%$ & $-22.3 \%$ \\
\hline 2 & $\mathrm{~kW} /$ Ton , Comstock [6] & $0.4 \%$ & $0.2 \%$ & $-1.2 \%$ & $-0.8 \%$ \\
\hline
\end{tabular}

\begin{tabular}{|c|l|c|c|c|c|}
\hline No & Refrigerant berlebih & Level 1 & Level 2 & Level 3 & Level 4 \\
\hline 1 & $\mathrm{~kW} /$ Ton & $10.4 \%$ & $16.6 \%$ & $-0.7 \%$ & $9.5 \%$ \\
\hline 2 & $\mathrm{~kW} /$ Ton , Comstock [6] & $1.8 \%$ & $2.5 \%$ & $4.9 \%$ & $9.0 \%$ \\
\hline
\end{tabular}

\begin{tabular}{|c|l|c|c|c|c|}
\hline No & Pelumas berlebih & Level 1 & Level 2 & Level 3 & Level 4 \\
\hline 1 & $\mathrm{~kW} /$ Ton & $-30.5 \%$ & $-11.4 \%$ & $-10.4 \%$ & $-10.6 \%$ \\
\hline 2 & $\mathrm{~kW} /$ Ton , Comstock [6] & $0.7 \%$ & $1.3 \%$ & $2.8 \%$ & $5.8 \%$ \\
\hline
\end{tabular}

\begin{tabular}{|c|l|c|c|c|c|}
\hline No & Fouling kondensor & Level 1 & Level 2 & Level 3 & Level 4 \\
\hline 1 & kW/Ton & $13.8 \%$ & $21.9 \%$ & $22.1 \%$ & $4.3 \%$ \\
\hline 2 & kW/Ton, Comstock [6] & $0.8 \%$ & $0.9 \%$ & $1.9 \%$ & $4.1 \%$ \\
\hline
\end{tabular}

\begin{tabular}{|c|l|c|c|c|c|}
\hline No & Non condensables & Level 1 & Level 2 & Level 3 & Level 4 \\
\hline 1 & kW/Ton & $8.4 \%$ & $40.8 \%$ & $46.0 \%$ & $32.7 \%$ \\
\hline 2 & kW/Ton, Comstock [6] & $4.7 \%$ & $6.5 \%$ & $8.1 \%$ & $14.7 \%$ \\
\hline
\end{tabular}

\begin{tabular}{|c|l|c|}
\hline No & Katup ekspansi & Parameter \\
\hline 1 & $\mathrm{~kW} /$ Ton & $-7.2 \%$ \\
\hline 2 & $\mathrm{~kW} /$ Ton, Comstock [6] & $1.7 \%$ \\
\hline
\end{tabular}

Meningkatknya $\mathrm{kW} /$ Ton chiller pada saat jumlah refrigerant berkurang, disebabkan oleh beberapa hal[6]. Pertama, adanya faktor keamanan yang cukup tinggi untuk jumlah refrigerant didalam chiller. Kedua adalah kemampuan katup ekspansi dalam mempertahankan tekanan di evaporator sampai derajat tertentu dengan cara membuka katup ekspasi lebih lebar. Ketika katup ekpansi tidak dapat mempertahankan tekanan didalam evaporator, tekanan evaporator akan turun dan temperatur superheat disisi keluar evaporator akan meningkat [6].

Kegagalan berikutnya adalah kapasitas refrigeran yang berlebihan. Jenis disimulasikan dengan menambah volum refrigeran kelipatan $10 \%$ untuk masing-masing level kegagalan. Dengan bertambahnya jumlah refrigeran di sistim chiller, konsumsi energi $\mathrm{kW} / \mathrm{Ton}$ cenderung meningkat, hal yang sama juga didapat oleh Comstock (Tabel 2), kondisi yang berbeda hanya pada kegagalan level 3. Dimana konsumsi energi $\mathrm{kW} /$ Ton sedikit menurun

Untuk kegagalan karena jumlah minyak pelumas yang berlebih didalam sistim, terjadi pengurangan konsumsi energi $\mathrm{kW} /$ Ton untuk tiap level kegagalan yang cukup besar (Tabel 2), hal ini sangat bertolak belakang dengan hasil yang diperoleh Comstock, dimana terjadi peningkatan konsumsi energi kW/Ton (Tabel 2). Peningkatan konsumsi energi ini terjadi karena pelumas yang berlebih mengisi ruang kosong yang terdapat pada kompressor dan menggenangi sistim transmisi roda gigi secara berlebihan, hal ini menyebabkan kerugian mekanis yang lebih besar pada kompresor (6).

Pengaruh fouling pada kondensor terhadap kW/Ton chiller bisa dilihat di Tabel 2. Pada setiap level kegagalan jenis ini, $\mathrm{kW} / \mathrm{T}$ on chiller akan naik. Untuk jenis kegagalan level 3 memiliki kenaikan $\mathrm{kW} /$ Ton yang lebih besar dibandingkan dengan kegagalan level 4. Hal ini 
sedikit berbeda dengan hasil yang diperoleh Comstock [Tabel 2], kenaikan kW/Ton semakin besar dengan bertambahnya level kegagalan. Akan tetapi secara trend memiliki kecendurungan sama dengan hasil penelitian kami.

Untuk mensimulasikan jenis kegagalan yang diakibatkan oleh adanya non-condesable gas didalam refrigerant maka ditambahkan gas nitrogen kedalam chiller secara bertahap, mulai dari $1 \%, 2 \%, 3 \%$, dan 5\%. Setiap level kegagalan dapat dilihat pengaruhnya terhadap KW/TON chiller di Tabel 2. Semakin besar kandungan nitrogen didalam refrigerant maka semakin turun kinerja chiller ( $\mathrm{kW} /$ Ton naik). Kenaikan kW/Ton chiller mulai dari $8.4 \%$ (Kegagalan Level 1) sampai dengan $32.7 \%$ (Kegagalan Level 4). Trend yang dihasilkan hampir sama dengan yang diperoleh oleh Comstock [6].

Untuk kegagalan katup ekspansi hanya memiliki satu level kegagalan, tidak seperti jenis kegagalan yang lain yang memiliki 4 level kegagalan. $\mathrm{kW} / \mathrm{Ton}$ chiller turun untuk kegagalan katup ekspansi. Hasil yang didapat oleh Comstock justru berlawanan, dimana $\mathrm{kW} /$ Ton chiller naik karena kerusakan pada katup ekspansi.

Trend memiliki kesamaan jika dibandingkan dengan hasil yang diperoleh Comstock pada empat jenis kegagalan yaitu debit air kondensor dan evaporator, fouling pada kondensor, dan non-condensable gas. Yang paling besar pengaruhnya terhadap $\mathrm{kW} / \mathrm{Ton}$ chiller adalah debit air kondensor (Rata-rata $45 \%$ ), kemudian disusul olen non-condensable gas (Rata-rata 32\%), lalu debit air kondensor (21\%), dan yang terakhir adalah fouling pada kondensor (Rata-rata 15\%). Walaupun secara trend sama akan tetapi secara presentase memiliki nilai yang berbeda dengan hasil yang didapat Comstock.

Terdapat juga hasil yang trendnya bertolak belakang dengan yang diperoleh Comstock yaitu berlebihnya pelumas pada kompresor dan kerusakan pada katup ekspansi. Dan jenis kegagalan lainnya memiliki hasil kombinasi, sebagian memiliki trend yang sama dan sebagian level kegagalan memiliki trend yang berbeda. Contohnya adalah kebocoran refrigerant (Trend berbeda di level kegagalan 1 dan 2), dan refrigerant berlebih (Trend berbeda di level kegagalan 3),

Deviasi parameter operasi chiller (kW/Ton) akibat delapan jenis kegagalan ini secara trend ada yang memiliki hasil yang bertolak belakang dan secara nilai absolut (Persentase) juga memiliki perbedaan. Perbedaan ini bisa disebabkan oleh beberapa hal:

Pertama adalah perbedaan dalam jenis yang regresi yang digunakan. Comstock menggunakan regresi tiga variabel seperti dalam persamaan (1). Dalam menggambarkan grafik dari persamaan yang didapat dari regresi tiga variabel, Comstock tidak hanya menggunakan beban evaporator sebagai input akan tetapi memasukkan dua jenis variabel tambahan yaitu temperatur air keluar evaporator (TEO) dan temperatur air masuk kondensor (TCI). Sebagai contoh bisa dilihat di Gbr 2, bahwa perbedaan deviasi parameter TCO-TCI tidak hanyak dipengaruhi oleh beban evaporator akan tetapi juga dipengaruhi oleh nilai TEO dan TCI. Sedangan untuk regresi satu variabel, grafik digambarkan hanya berdasarkan input nilai beban evaporator, sedangkan nilai TEO dan TCI untuk masing-masing titik adalah nilai rill.

Faktor kedua adalah perbedaan dalam satuan yang digunakan. Comstock menggunakan satuan Fahrenheit untuk temperatur, sedangkan penelitian ini menggunakan satuan Celcius. Sebagai contoh kenaikan suhu dari $50^{\circ} \mathrm{C}$ $\left(122^{\circ} \mathrm{F}\right) \mathrm{ke} 100^{\circ} \mathrm{C}\left(212^{\circ} \mathrm{F}\right)$ adalah sebesar $100 \%$ untuk satuan Celcius, sedangkan untuk satuan Fahrenheit kenaikan yang terjadi hanya $74 \%$. Sehingga perbedaan persentase deviasi tidak dapat dihindarkan dalam membandingkan hasil yang kami peroleh dengan yang didapat oleh Comstock. Kecuali untuk daya kompressor, Comstock menggunakan satuan SI yaitu kW.

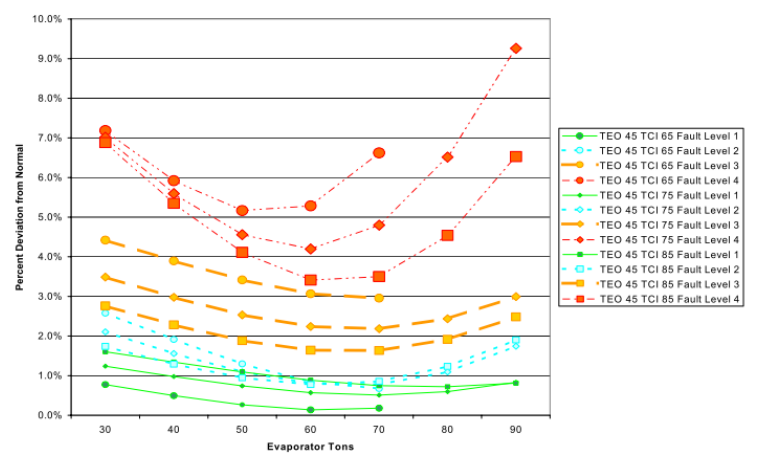

Gambar 2. Deviasi kW/Ton akibat pelumas berlebih 


\section{KESIMPULAN}

Berdasarkan hasil analisa dapat disimpulkan bahwa naiknya konsumsi energi chiller (kW/Ton) akibat kegagalan yang paling besar pengaruhnya adalah kepada kegagalan karena berkurangnya debit air evaporator (Ratarata 45\%), kemudian disusul oleh kandungan non-condensable gas (32\%), lalu dibawahnya adalah berkurangnya debit air kondensor $(21 \%)$ dan yang terakhir adalah fouling pada kondensor (15\%). Trend yang bertolak belakan dan perbedaan presentase dengan yang diperoleh Comstock kemungkinan diaakibatkan oleh perbedaan dalam jenis regresi yang digunakan dan berpengaruh dalam menggambarkan grafiknya, kedua adalah satuan yang digunakan juga berbeda.

\section{REFERENSI}

[1] Nofirman Firdaus, Bambang Teguh Prasetyo \& Thomas Luciana (2016)." Chiller: Performance Deterioration and Maintenance". Energy Engineering, 113:4, 55-80

[2] JAYAPRAKASH SATHTHASIVAM, GARY TANG, and KIM CHOON NG (2010). Evaluation of the simple thermodynamic model (Gordon and NG universal chiller model) as a fault detection and diagnosis tool for on-site centrifugal chillers. Int. J. Air-Cond.
[3] Blahnik, D.E.Klein,R.F.(1993). Aging Assessment of Essential HVAC Chillers Used in Nuclear Power Plants.Phase I. NUREG/CR-6043. PNL-8614. Vol 1. Pacific Northwest Laboratory.

[4] Piper, James E (1999).Operation and maintenance manual for energy management. ME Sharpe Inc.

[5] Mathew C. Comstock. James E. Braun. (1999). EXPERIMENTAL DATA FROM FAULT DETECTION AND DIAGNOSTIC STUDIES ON A CENTRIFUGAL CHILLER. ASHRAE Research Project 1043-RP

[6] Mathew C. Comstock. James E. Braun. (1999). DEVELOPMENT OF ANALYSIS TOOLS FOR THE EVALUATION OF FAULT DETECTION AND DIAGNOSTICS FOR CHILL. ASHRAE Research Project 1043-RP

[7] Mathew C. Comstock. James E. Braun. EA, Groll (1999)."The Sensitivity of Chiller Performance to CommonFaults". HVAC \&R Research, 7:3, 263-279. (2001)

[8] Comstock, Matthew C. Braun, James E. Groll, Eckhard A. (2002). "A survey of common faults for chillers". ASHRAE Transactions; Atlanta Vol. 108, (2002): 819 